\title{
Use of inhaled nitric oxide for emergency Cesarean section in a woman with unexpected pri- mary pulmonary hypertension
}

\author{
[L'inbalation d'oxyde nitrique pour la césarienne d'urgence associée à une \\ bypertension pulmonaire primitive inattendue]
}

Christopher Decoene MD, ${ }^{*}$ Karim Bourzoufi MD, $\dagger$ Didier Moreau MD, ${ }^{*}$ Fabrice Narducci MD, $\ddagger$

Francis Crepin MD, ${ }^{*}$ Renee Krivosic-Horber MD $\dagger$

Purpose: Use of inhaled nitric oxide (iNO) could be of importance in emergency cases of primary pulmonary hypertension (PPH) in pregnant patients during labour and delivery. iNO acts as a selective pulmonary bed vasodilator avoiding systemic hemodynamic effects due to its ease of administration. Pulmonary bed vasodilation improves right ventricular function directly and left ventricular function indirectly.

Clinical features: We report the case of a pregnant patient with unexpected PPH in whom an emergency Cesarean section (CS) had to be performed. PPH was diagnosed on admission as she arrived in active labour at 34 weeks gestational age. An emergency CS was performed under epidural anesthesia for breech presentation . All along labour, delivery and the first $24 \mathrm{hr}$, iNO was administered via a noninvasive ventilation device. CS was uneventful. A severe pulmonary hypertensive crisis was observed $12 \mathrm{hr}$ after delivery and resolved with an increase of iNO concentration and administration of isoprenalin. The patient and baby returned home on day ten.

Conclusion: The ease of administration of $\mathrm{NO}$ allowed the optimal control of pulmonary arterial hypertension. No interaction with epidural anesthesia was observed. Use of iNO can improve the management of urgent $\mathrm{CS}$ in women with unexpected $\mathrm{PPH}$.

Objectif : L'utilisation d'une inhalation d'oxyde nitrique (iNO) pendant le travail et l'accouchement peut devenir une mesure d'urgence importante dans le contexte d'une hypertension pulmonaire primitive (HPP) imprévue chez des femmes enceintes. Étant donné la facilité de son administration, l'iNO agit comme un vasodilatateur sélectif du lit pulmonaire en prévenant des effets hémodynamiques généralisés. La vasodilatation du lit pulmonaire améliore directement la fonction ventriculaire droite et indirectement celle du ventriculaire gauche.

Éléments cliniques: Nous citons le cas d'une femme enceinte qui a présenté une HPP et qui a dû subir une césarienne d'urgence. L'HPP a été diagnostiquée au moment de l'admission de la patiente en travail actif, à 34 sem de grossesse. Une césarienne d'urgence a été réalisée sous anesthésie péridurale pour une présentation du siège. Tout au long du travail, de l'accouchement et des 24 premières $h$, l'iNO a été administré au moyen d'un dispositif de ventilation non effractif. La césarienne s'est bien déroulée. Une crise d'hypertension pulmonaire sévère a été observée 12 h après l'accouchement et traitée avec une concentration augmentée d'iNO et l'administration d'isoprénaline. La patiente et le bébé sont retournés à la maison le dixième jour.

Conclusion : La facilité d'administration de l'iNO a permis un contrôle optimal de l'hypertension artérielle pulmonaire. Aucune interaction avec l'anesthésie péridurale n'a été observée. L'usage d'iNO peut améliorer la conduite d'une césarienne d'urgence chez les patientes qui présentent une HPP inattendue.

Case report

Primary pulmonary hypertension $(\mathrm{PPH})$ is a rare disease. ${ }^{1,2}$ PPH may complicate pregnancy and is associated with a high risk of maternal death. ${ }^{1,2}$ A maternal mortality rate of up to $50 \%$ and sudden irreversible deterioration in the postpartum period has been reported. ${ }^{3}$ Cesarean section (CS) in a pregnant

From the Clinic of Anesthesiology and Reanimation in cardiovascular diseases, ${ }^{*}$ the Department of Anesthesiology and Reanimation I, $\dagger$ and the Jeanne de Flandres Obstetrical Clinic, ‡ Lille, France.

Address correspondence to: Dr. Christopher Decoene, Cardiologic hospital, CHRU Lille, 59037 Lille, France. Phone: 33320445352 ; Fax: 33320444810; E-mail: c-decoene@ chru-lille.fr

Institution to which the work should be attributed: Clinic of Anesthesiology and Reanimation in cardiovascular diseases, CHRU Lille, France Accepted for publication January 4, 2001.

Revision accepted March 9, 2001. 
woman with PPH presents an enormous challenge for the anesthesiologist. ${ }^{4}$

Impaired pulmonary vascular endothelial nitric oxide production plays a role in the pathogenesis of $\mathrm{PPH}^{5}$ For a decade, inhaled nitric oxide ( $\left.i \mathrm{NO}\right)$ has been used as a specific pulmonary vascular bed vasodilator, ${ }^{5}$ thus improving right ventricular function by decreasing pulmonary hypertension. ${ }^{6}$

Recently $i \mathrm{NO}$ has been used in pregnant patients with Eisenmenger's syndrome resulting in reduced hypoxemia and pulmonary artery pressure (PAP) although the patients died. ${ }^{7,8}$ In this article we report the management and hemodynamic profile of a pregnant patient with PPH in whom we used $i \mathrm{NO}$ to control PAP during CS and in the postpartum period.

A 33-yr-old woman, (para 2, gravida 2), presented at 34 weeks gestational age to our high-risk pregnancy hospital with increased dyspnea and uterine contractions. She was $1.52 \mathrm{~m}$ tall and weighed $58 \mathrm{~kg}$ (50 $\mathrm{kg}$ before pregnancy). Her past medical history revealed only asthma. She had no signs of connective tissue disorders and had never used anorectic agents. Two years before she had an uneventful term CS for fetopelvic disproportion at full-term. The present pregnancy had been uneventful and fetal growth was normal. On initial clinical examination, there were no signs of right or left ventricular failure, only a mild dyspnea at rest.

Investigation of the dyspnea was initiated. The electrocardiogram (ECG) showed normal sinus rhythm, right axis deviation and right atrial hypertrophy. The echocardiography study demonstrated a normal left ventricular function, a hypertrophic and dilated right ventricle with right to left septal shift, a mild tricuspid regurgitation and a dilated right atrium. Systolic PAP was estimated at 90-100 $\mathrm{mmHg}$. No cardiomyopathy, a closed foramen ovale and no sign of pulmonary embolism (normal ventilation/perfusion scan and a negative D-dimer test) eliminated a secondary pulmonary hypertension. Active labour began four hours after admission. A breech presentation and a previous CS mandated a repeat CS.

Intraoperative management consisted of ECG and pulse oxymetry $\left(\mathrm{SpO}_{2}\right)$ monitoring. An arterial line and a pulmonary artery catheter (PAC) were inserted for the continuous monitoring of mean arterial pressure (MAP), mean PAP (MPAP), mean right atrial pressure (MRAP), mixed venous oxygen saturation $\left(\mathrm{SMVO}_{2}\right)$ and, when needed, cardiac index (CI; Table). Noninvasive ventilation (ServoA300®, Siemens medical, France) was initiated via a tight fitting face mask to administer $i \mathrm{NO}$ at a concentration of $5 \mathrm{ppm}$ and an inspired oxygen fraction $\left(\mathrm{F}_{1} \mathrm{O}_{2}\right)$ of $30 \%$. NO and nitro-
TABLE Perioperative hemodynamic and respiratory parameters

\begin{tabular}{|c|c|c|c|c|c|c|c|c|}
\hline & $B$ & $I$ & $E$ & $P$ & 1 & 12 & 24 & 48 \\
\hline HR (bpm) & 98 & 110 & 90 & 112 & 73 & 30 & 91 & 81 \\
\hline \multicolumn{9}{|l|}{$\mathrm{SAP}(\mathrm{mmHg})$} \\
\hline Systolic (mmHg) & 128 & 128 & 132 & 115 & 110 & $<40$ & 108 & 115 \\
\hline Diastolic (mmHg) & 70 & 68 & 64 & 62 & 51 & $<40$ & 60 & 58 \\
\hline $\mathrm{MAP}(\mathrm{mmHg})$ & 88 & 86 & 86 & 74 & 72 & $<40$ & 71 & 74 \\
\hline MPAP (mmHg) & 55 & 37 & 36 & 45 & 24 & 80 & 37 & 33 \\
\hline MRAP (mmHg) & 5 & 4 & 3 & 8 & 3 & 18 & 5 & 6 \\
\hline $\mathrm{CI}\left(\mathrm{L} \cdot \mathrm{min}^{-1} \cdot \mathrm{m}^{-2}\right)$ & 2.2 & 3.7 & 3.6 & 2.4 & 3.8 & nd & 2.7 & 3.5 \\
\hline PVR (dynes $\cdot \sec \cdot \mathrm{cm}^{5}$ ) & 850 & 421 & 449 & 734 & 266 & nd & 590 & 420 \\
\hline $\mathrm{PaO}_{2}(\mathrm{mmHg})$ & 155 & 145 & 162 & 156 & 135 & 126 & 106 & 78 \\
\hline $\mathrm{SMVO}_{2}(\%)$ & 68 & 71 & 72 & 69 & 74 & 30 & 68 & 66 \\
\hline $\mathrm{PaCO}_{2}(\mathrm{mmHg})$ & 33 & 32 & 32 & 35 & 33 & 35 & 32 & 33 \\
\hline $\mathrm{pH}$ & 7.43 & 7.45 & 7.44 & 7.41 & 7.43 & 7.40 & 7.44 & 7.46 \\
\hline
\end{tabular}

At each perioperative time, relative to Cesarean section, a set of hemodynamic and respiratory parameters is presented. For perioperative time period, $\mathrm{B}=$ baseline prior to $i \mathrm{NO}$ and epidural anesthesia; $\mathrm{I}=i \mathrm{NO} ; \mathrm{E}=$ epidural blockade up to $\mathrm{T} 6$ combined with $i \mathrm{NO}$; $\mathrm{P}=$ during placenta removal; $1,12,24$ and $48 \mathrm{hr}=$ postoperative values; $\mathrm{HR}=$ heart rate, bpm=beats per minute $\mathrm{SAP}=$ systemic arterial pressure; $\mathrm{MAP}=$ mean arterial blood pressure; $\mathrm{MPAP}=$ mean pulmonary arterial pressure; $\mathrm{MRAP}=$ mean right atrial pressure $(\mathrm{mmHg}) ; \mathrm{CI}=$ cardiac index $\left(\mathrm{L} \cdot \mathrm{min}^{-1} \cdot \mathrm{m}^{-2}\right) ; \mathrm{PVR}=$ pulmonary vascular resistance $\left(\right.$ dynes $\left.\cdot \mathrm{sec} \cdot \mathrm{cm}^{-5}\right) ; \mathrm{PaCO}_{2}=$ arterial pressure of carbon dioxide; $\mathrm{PaO}_{2}=$ oxygen arterial pressure; $\mathrm{SMVO}_{2}=$ mixed venous oxygen saturation (\%); nd=not done;

gen dioxide $\left(\mathrm{NO}_{2}\right)$ concentrations were controlled by a $\mathrm{NO} / \mathrm{NOO}$ electrochemical analyzer (Siemens medical, France). $i$ NO induced a decrease in MPAP and an increase in CI ( 55 vs $37 \mathrm{mmHg}$ and 2.2 vs 3.71 $\mathrm{m} \mathrm{m}^{-1} \cdot \mathrm{m}^{-2}$ respectively). An epidural catheter was inserted in the L2-L3 space. After ten minutes, $25 \mathrm{mg}$ of bupivacaine $(10 \mathrm{~mL}$ of $0.25 \%$ solution), $100 \mathrm{mg}$ of lidocaïne $(10 \mathrm{~mL}$ of $1 \%$ solution $)$ and $20 \mu \mathrm{g}$ of sufentanil were injected by small incremental doses to obtain epidural blockade up to the level of the T6 dermatome bilaterally. Hemodynamic parameters remained stable with epidural anesthesia and $i \mathrm{NO}$, and CS was uneventful. Only an increase of MPAP from $33 \mathrm{mmHg}$ to 45 $\mathrm{mmHg}$ was observed during manual delivery of the placenta. This event lasted for five minutes and resolved spontaneously. Neonatal Apgar scores were 10 at one and ten minutes, and the baby weighed $2520 \mathrm{~g}$. Both the baby's and the mother's methemoglobin concentration were unmeasurable. Umbilical cord blood gas and $\mathrm{pH}$ measurements were normal. Oxytocin infusion (10 UI in $30 \mathrm{~min}$ ) did not alter hemodynamic parameters. Fluids were administered cautiously under strict hemodynamic monitoring to prevent right ventricular overload. Blood loss was estimated to be approximately $300 \mathrm{~mL}$. Total fluid administration during CS was $500 \mathrm{~mL}$ for a urine output averaging $1.5 \mathrm{~mL} \cdot \mathrm{kg}^{-1} \cdot \mathrm{hr}^{-1}$. 
Postoperatively, the patient was transferred to the intensive care unit (ICU). Noninvasive ventilation with $i \mathrm{NO}(5 \mathrm{ppm})$ and a $30 \% \mathrm{~F}_{1} \mathrm{O}_{2}$ was continued. One hour postoperatively, sufentanil (10 $\mu \mathrm{g})$ and bupivacaine $(20 \mathrm{mg}, 16 \mathrm{~mL}$ of $0.125 \%$ solution) were injected, the epidural catheter was removed and an iv infusion of heparin was initiated $\left(0.1 \mathrm{UI} \cdot \mathrm{kg}^{-1} \cdot \mathrm{min}^{-1}\right)$. Twelve hours after CS, a sudden increase in MPAP and MRAP with a drop in systemic arterial pressure, bradycardia, loss of consciousness and respiratory arrest occurred in an otherwise asymptomatic and pain-free patient. Tracheal intubation was required for $30 \mathrm{mn}, i \mathrm{NO}$ was increased to $15 \mathrm{ppm}$ and isoprenaline (0.16 $\mathrm{mg}$ in four minutes) and dobutamine (20 $\left.\mu \mathrm{g} \cdot \mathrm{kg}^{-1} \cdot \mathrm{min}^{-1}\right)$ were started. Spontaneous breathing and consciousness were regained in less than five minutes, PAP decreased and arterial pressure returned to its initial level in $30 \mathrm{~min}$. Over the next $12 \mathrm{hr}$ all $i v$ drugs were progressively decreased and replaced by an $i v$ calcium blocker (nicardipine, $1 \mu \mathrm{g} \cdot \mathrm{kg}^{-1} \cdot \mathrm{mn}^{-1}$ ). iNO ( 5 ppm) was continued 24 hr after CS and then gradually weaned over a $24 \mathrm{hr}$ period, while replacement by $i v$ nicardipine was monitored with echocardiography and PAP. Oral nicardipine (150 mg daily) and oral anticoagulation were started on the third postoperative day. The patient returned home on the tenth postoperative day able to care for her baby.

\section{Discussion}

High pulmonary pressures directly induce right ventricular dysfunction by pressure overload with a shift to the right of the Starling curve. Thus, an increase in preload, as seen during pregnancy (increase in blood volume and cardiac output) can easily result in right ventricular failure. ${ }^{3-8} \mathrm{PPH}$ indirectly alters left ventricular function due to a decrease in left ventricular preload and ventricular interdependence (via septal wall motion of the overloaded right ventricle). ${ }^{9}$ Decrease in pulmonary hypertension lowers right ventricular afterload, improves right ventricular ejection fraction, decreases right ventricular work and size and improves both diastolic and systolic left ventricular function. ${ }^{6-9}$

The response of pulmonary arteries to vasodilation is important in the outcome of $\mathrm{PPH}$ in pregnant women. $^{3} i \mathrm{NO}$ is a potent selective pulmonary vasodilator. ${ }^{5}$ Only a few reports on the use of $i \mathrm{NO}$ during delivery in patients with Eisenmenger's syndrome have been published. In most of the cases secondary pulmonary hypertension was known, explored, and response to vasodilators had been tested before delivery. In this case, $\mathrm{PPH}$ was unexpected and the team only had a few hours to test the pulmonary artery response to $i \mathrm{NO}$. Since the response was favourable, $i \mathrm{NO}$ was administered all along the $\mathrm{CS}$ and into the postoperative period.

The effect of $i \mathrm{NO}$ on PAP must be monitored to confirm its effectiveness. Although use of the PAC is controversial and should be assessed on a case by case basis to ensure an optimal benefit-risk ratio, ${ }^{1}$ PAC proved useful to monitor $i \mathrm{NO}$ effect directly, to manage right ventricular preload and to detect a pulmonary hypertensive crisis. Pulmonary artery occlusion pressure was never measured in order to limit the risks of pulmonary artery rupture. Noninvasive transthoracic echocardiography is difficult in the operative room and prolonged use of the transesophageal route is excluded in an awake patient. Therefore, unfortunately, we were not able to report diastolic and systolic left ventricular function during the course of CS. Association of $i \mathrm{NO}$ with epidural anesthesia resulted in no untoward effect on arterial pressure, confirming the selective pulmonary artery vasodilator effect of $i$ NO. During CS, PAP increased only during the removal of the placenta. $\mathrm{O}$ ' Hare et al. have reported difficulties to control MPAP with nitroglycerin after delivery of the baby and removal of the placenta. ${ }^{10}$ This could be related to physiological uterine contractions restoring blood to the mother and resulting in volume overload. ${ }^{10}$ Others factors could be contributive such as the emotional response to childbirth. $i$ NO facilitated, probably more than nitroglycerin, adaptation of the right ventricle to preload variations during this period and during oxytocin infusion.

$i \mathrm{NO}$ has three main side effects: an increase in bleeding time, methemoglobin formation and risk of injury to the pulmonary tract. The increase in bleeding time, if any, was of no apparent consequence. No signs of epidural hematoma were detected. No hemostatic abnormalities were observed in the operative field during the CS. Moreover the increase in bleeding time may be of value in the postoperative course, limiting pulmonary microembolism. As $i$ NO improved right ventricular function and had no untoward effect on arterial pressure, and apparently, bleeding under epidural anesthesia, $i \mathrm{NO}$ seems to have more benefits than risks when used during delivery in $\mathrm{PPH}$ patients under epidural anesthesia. Methemoglobin formation is dangerous and can be transmitted to the fetus before CS. In this case methemoglobin concentration was unmeasurable immediately after birth and umbilical cord blood gas and $\mathrm{pH}$ were within the normal range. Administration of $i \mathrm{NO}$ requires precautions. $i$ NO must be delivered close to the patient's airway to limit chemical reaction with oxygen resulting in a toxic nitrogen dioxide production. We chose a noninvasive ventilation by face mask although it can be 
uncomfortable. Others have reported administration through a nasal canula. ${ }^{6,7}$ In all cases, inspired nitric oxide and $\mathrm{NO}_{2}$ must be monitored to avoid iatrogenic injury to the pulmonary tract. ${ }^{5}$

The risk of sudden death mandates close monitoring of the patient in the ICU during the first postoperative days. In this case, a pulmonary hypertensive crisis with acute right ventricular failure occurred $12 \mathrm{hr}$ postoperatively, the causes of which remained unclear. The postoperative fluid shift, as seen after Cesarean section and pregnancy, may not have been the sole factor to explain the right ventricular failure. ${ }^{1-3}$ Pulmonary microembolism cannot be excluded although heparin and $i \mathrm{NO}$ were used for prevention. Sudden return of sympathetic tone at the end of epidural blockade may have contributed to the increase in venous return and volume overload. Finally, hypoxemia cannot be excluded although analyses of the $\mathrm{SpO}_{2}$ data (minute per minute) did not find any change before the acute increase in PAP.

This successful use of $i \mathrm{NO}$ underlines the importance of PAP control during CS and the postpartum period in women with unexpected PPH. $i \mathrm{NO}$ is one of the most appropriate pulmonary vasodilators when a reversible component is present due to its route of administration, its pharmacokinetic properties, its lack of interference with anesthesia and absence of effects on the baby. Anesthesiologists should be aware of the benefits of $i \mathrm{NO}$ especially when faced with labour, delivery or CS in a pregnant woman with unexpected PPH.

\section{References}

1 Smedstad KG, Cramb R, Morison DH. Pulmonary hypertension and pregnancy: a serie of eight cases. Can J Anaesth 1994; 41: 502-12.

2 Weiss BM, Zemp L, Seifert B, Hess OM. Outcome of pulmonary vascular disease in pregnancy: a systematic overview from 1978 through 1996. J Am Coll Cardiol 1998; 31: 1650-7.

3 Easterling TR, Ralph DD, Schmucker BC Pulmonary hypertension in pregnancy : treatment with pulmonary vasodilators. Obstet Gynecol 1999; 93: 494-8.

4 Weeks SK, Smith JB. Obstetric anaesthesia in patients with primary pulmonary hypertension (Editorial). Can J Anaesth 1991; 38: 814-6.

5 Hart CM. Nitric oxide in adult lung disease. Chest 1999; 115: 1407-17.

6 Frostell CG, Blomqvist H, Hedenstierna G, Lundberg J, Zapol WM. Inhaled nitric oxide selectively reverses human hypoxic pulmonary vasoconstriction without causing systemic vasodilation. Anesthesiology 1993; 78: 427-35.

7 Goodwin TM, Gherman RB, Hameed A, Elkayam U. Favorable response of Eisenmenger syndrome to inhaled nitric oxide during pregnancy. Am J Obstet Gynecol 1999; 180: 64-7.

8 Lust KM, Boots RJ, Dooris M, Wilson J. Management of labor in Eisenmenger syndrome with inhaled nitric oxide. Am J Obstet Gynecol 1999; 181: 419-23.

9 Santamore WP, Dell'Italia LJ. Ventricular interdependence: significant left ventricular contributions to right ventricular systolic function. Prog Cardiovasc Dis 1998; 40: 289-308.

10 O'Hare R, McLoughlin C, Milligan K, McNamee D, Sidhu $H$. Anaesthesia for caesarian section in the presence of severe primary pulmonary hypertension. Br J Anaesth 1998; 81: 790-2. 